\title{
ANALYSIS ON DECENTRALIZED CLINICAL TRIALS IN SOME EUROPEAN COUNTRIES
}

\author{
Veska T. GERGOVA ${ }^{1,2}$, Asena H. SERBEZOVA ${ }^{1}$, Dobriana A. SIDJIMOVA ${ }^{1}$ \\ ${ }^{1}$ Faculty of Public Health "Prof. Tsekomir Vodenitcharov", Medical University-Sofia, Sofia, Bulgaria \\ ${ }^{2}$ Bulgarian Drug Agency, Sofia, Bulgaria
}

\author{
Received 01 Nov 2021, Accepted 23 Nov 2021 \\ https://doi.org/10.31688/ABMU.2021.56.4.01
}

\begin{abstract}
Introduction. Sponsors of clinical trials propose variations of home visits and virtual contact points with the patients instead of visits at the clinical sites, as well as other digital and remote solutions.

The objective of the study was to search and analyse the experience and practice of European countries on applying decentralized elements and a hybrid approach of conducting clinical trials' activities and procedures, as well as to establish the applicable rules and regulation.

Material and methods. A questionnaire survey was conducted among European countries in the period December 2020 - February 2021, by email communication.
\end{abstract}

Results. In most of the countries, it was not forbidden, and respondents indicated the opportunity of medical specialists to help patients at their home. $37.50 \%$ of the countries indicated that the applicable legislation cannot be related to the medical or clinical trials legislation or national commercial law but "Other". Based on the practice, all or some of the activities can be done as a home care. $68.75 \%$ responded negatively to the application of the "site-less" model, but $81.25 \%$ considered that the combination of on-site and home visits can be better than only visits at sites.

Conclusion. Based on this research, the implementation of decentralized elements in the clinical trials

\section{Résumé}

Analyse des essais cliniques décentralisés dans certains pays européens

Introduction. Les promoteurs d'essais cliniques offrent des options de visites à domicile et de points de contact virtuels avec les patients au lieu des visites dans les centres cliniques, ainsi que d'autres solutions numériques et à distance.

L'objectif de l'étude était de rechercher et d'analyser l'expérience et la pratique des pays européens en matière d'application d'éléments décentralisés et d'une approche hybride par rapport à la conduite des activités et des procédures relatives aux essais cliniques, ainsi que d'établir les règles applicables et la réglementation pertinente.

Matériel et méthodes. Une enquête par courriel a été menée dans les pays européens pendant la période comprise entre décembre 2020 et février 2021.

Résultats. Dans la plupart des pays ce n'était pas interdit et les répondants ont indiqué la possibilité pour les professionnels de la santé d'aider leurs patients à domicile. $37,50 \%$ des pays ont indiqué que les dispositions de la législation applicable ne pouvaient pas être renvoyées à la législation médicale, à la législation relative aux essais cliniques ou au droit commercial national, mais plutôt à « Autre ». Sur la base de la pratique, 
in Europe is often based on a case-by-case evaluation only. Notwithstanding the application of various national requirements and acts, they are either fragmentary, or not specifically applicable for such cases.

Keywords: patient-centred, home visit, clinical trial, European countries.

\section{List of abbreviations:}

ICH - International Conference of Harmonization GCP - Good Clinical Practice

IMP - Investigational medicinal product toutes ou certaines des activités peuvent être effectuées comme soins à domicile. En ce qui concerne l'application du modèle «centres-free», $68,75 \%$ des répondants ont donné une réponse négative, mais $81,25 \%$ parmi eux estiment que la combinaison de visites dans les centres cliniques et à domicile peut s'avérer meilleure que l'option de visites seules dans les centres.

Conclusion. Sur la base de cette étude, l'application d'éléments décentralisés par rapport aux essais cliniques en Europe n'est souvent fondée que sur seule l'évaluation de chaque cas individuel. Malgré l'application de différents exigences et documents nationaux, ceux-ci sont soit fragmentaires, soit ne s'appliquent pas à de tels cas de manière spécifique.

Mots-clés: centré sur le patient, visite à domicile, essai clinique, pays européens.

The question regarding the responsibilities is clarified in the International Conference of Harmonization (ICH) Good Clinical Practice (GCP) E6 (R2), point 4.2.5, as follows: "The investigator is responsible for supervising any individual or party to whom the investigator delegates trial-related duties and functions conducted at the trial site" ${ }^{8}$. In addition, point 4.2.6 gives a guaranty for the appropriateness of the third-party's qualification and "integrity of the trial-related duties and functions performed, and any data generated" 8 . Further clarification regarding this practice is recognized by GCP-Inspectors Working Group as required to avoid unclear separation of responsibilities and roles?.

The European Union Guidance on the management of clinical trials during the COVID-19 pandemic, in its introduction, states that: "Where a trial participant is unable to attend the site, other measures, such as home nursing, if possible given social distancing needs, or contact via phone or telemedicine, may be required to identify adverse events and ensure continuous medical care and oversight. However, the limitations and risks of such methods and the requirements for data protection should be considered and such alternative arrangements need to be adequately documented"10.

There is a recommendation about the substantial amendments of a clinical trial to follow the national requirements and to be approved by the competent authorities, except cases where the need to assure the safety of the participants prevails ${ }^{10,11}$.

However, legal framework and limitations are not provided by the European Union law and the applications of these opportunities and additional arrangements may differ significantly from country to country. 
THE OBJeCtive OF THE STUDY was to search and analyse the experience and practice of European countries on applying decentralized elements and a hybrid approach of conducting clinical trials' activities and procedures, as well as to establish the applicable rules and regulation.

\section{Materials AND Methods}

A questionnaire-based survey was conducted among European countries (Annex 1). The countries were represented by employees of the National Competent Authority on medicines, but their responses cannot be considered as the official position of the authority. The questionnaire was conducted in the period December 2020 - February 2021 by email communication. The aim was that each country shares experiences and practices, especially those applied during the COVID-19 pandemic, on the options for conducting clinical trials in exceptional circumstances.

The questionnaire included eight questions on decentralized elements in clinical trials and asked for relevant practice, guidelines and applicable specific and common medical or other national legislation. All the questions gave the opportunity for additional explanations to the answer and relevant information considered applicable by the respondent.

Two types of questions were included in the questionnaire: key issues, that are the main focus of this research, and optional questions about selected topics or additional information and sources. The countries' representatives were instructed to answer all the core questions and to give additional information according to their preferences. The results were processed with MS Office Windows 10. The information on web sources or national legislation was double checked and then the relevant link was provided in this research.

The main focus of this research is not the comparison between countries, but the findings of each individual country and the final common results.

\section{Results}

The survey was sent to all European Union/ European Economic Area member states and Switzerland, with a request for completion. A response was received from 16 countries - Austria, Czech Republic, Denmark, Estonia, Finland, Germany, Hungary, Ireland, Latvia, Poland, Portugal, Romania, Slovakia, Slovenia, Spain, and Switzerland.

Regarding the question "Is it possible in your country that specialized service companies or medical care specialists work with sponsors and investigators to help patients (at their home) in the process of conducting clinical trials?" the most common answer was not "Yes, it is" or "No, it isn't" but "Other" with explanation (half of the countries, 50\%). 43.75\% of the countries stated that it is possible for such companies or medical specialists to help patients at their home in the country's territory. $6.25 \%$ of the countries gave answer "No, it isn't".

When asked for the relevant regulation of this service or companies (optional question) $37.50 \%$ of the countries indicated the answer "Other". The other part of the countries responded that the existing national regulation can be related to a certain part of the law - part of the medical legislation $(12.50 \%)$, part of the clinical trials legislation (6.25\%) or part of the national trade/commercial law (6.25\%). 37.50\% did not answer this question.

Table 1 shows the results of the countries' responses to the third question, regarding the services allowed to be provided as home care at the patient's home.

The highest level of possible application of the decentralized elements in clinical trials was represented by the question "Is the "site-less" model of clinical trials applicable in your country?". Most of the countries here responded negatively $(68.75 \%)$, while the positive answer "Yes, it is applicable" was only $18.75 \%$. Countries of these two groups gave additional information to their responses, by answering to the next two questions about the relevant provisions on the topic and applicable limitation/prohibition. The other countries did not give specific positive or negative answer on the application of "site-less" model, but the answer "Other" (12.50\%).

In the answers for the main challenges in the "site-less clinical trial model", the challenges identified by the respondents varied across the countries. The challenges were classified into nine groups: issues on 1) the responsibility in the clinical trial, 2) the qualification of the engaged personnel, 3) authorization of the clinical trial, 4) proper training of the personnel, 5) data protection, 6) storage and distribution of investigational medicinal product (IMP), 7) contracts between the relevant parties, 8) transparency and 9) data verification.

Regarding the question if they consider that the combination of home and on-site visits is better than visits at site only, all the countries that responded to this question $(81.25 \%)$ considered in their opinion that the combination can be better than only visits at sites. $18.75 \%$ of the countries did not answer this question (Ireland, Poland, and Spain). 
Table 1. Clinical trials' services allowed to be provided at the patient's home in European countries

\begin{tabular}{|c|c|c|c|c|c|c|c|}
\hline \multirow[b]{2}{*}{ Country } & \multicolumn{7}{|c|}{ Services } \\
\hline & $\begin{array}{c}\text { A. Treatment' } \\
\text { adminis- } \\
\text { tra-tion }\end{array}$ & $\begin{array}{l}\text { B. Monitoring } \\
\text { outcomes }\end{array}$ & $\begin{array}{l}\text { C. Distribution } \\
\text { of IMP }\end{array}$ & $\begin{array}{l}\text { D. Laboratory } \\
\text { specimen } \\
\text { collection and } \\
\text { processing }\end{array}$ & $\begin{array}{l}\text { E. Preparation } \\
\text { of IMP }\end{array}$ & $\begin{array}{l}\text { F. Assessment } \\
\text { of adverse } \\
\text { events and } \\
\text { reporting }\end{array}$ & G. Other \\
\hline Austria & yes & yes & $\begin{array}{c}\text { yes }^{*} \text { investiga- } \\
\text { tor-to-patient } \\
\text { shipment }\end{array}$ & yes & yes & yes & - \\
\hline $\begin{array}{c}\text { Czech } \\
\text { Republic }\end{array}$ & yes & yes & yes & yes & yes & $\begin{array}{l}\text { reporting } \\
\text { only }\end{array}$ & $\begin{array}{l}\text { as defined } \\
\text { in the trial's } \\
\text { protocol }\end{array}$ \\
\hline Denmark & yes $^{* *}$ & yes $^{* *}$ & yes $^{* *}$ & yes $^{* *}$ & yes $^{* *}$ & yes $^{* *}$ & - \\
\hline Estonia & yes & yes & yes & yes & yes & yes & case-by-case \\
\hline Finland & \multicolumn{7}{|c|}{ on case-by-case basis depending on the study protocol and the IMP } \\
\hline Germany & yes & $\begin{array}{l}\text { yes, but no } \\
\text { physical ex- } \\
\text { amination }\end{array}$ & - & $\begin{array}{l}\text { yes, without } \\
\text { processing }\end{array}$ & - & - & - \\
\hline Hungary & \multicolumn{7}{|c|}{ no specific answer service by service } \\
\hline Ireland & - & - & yes $^{*}$ & - & - & - & - \\
\hline Latvia & yes & - & yes & yes & - & - & - \\
\hline Poland & \multicolumn{7}{|c|}{ no specific answer service by service } \\
\hline Portugal & yes & yes & yes & yes & yes & yes & - \\
\hline Romania & - & $\begin{array}{c}\text { yes }^{* * *}, \text { by } \\
\text { investigational } \\
\text { team }\end{array}$ & $\begin{array}{l}\text { yes }^{* * *}, \text { by } \\
\text { courier only }\end{array}$ & - & - & $\begin{array}{l}\text { yes }^{* * *}, \text { by in- } \\
\text { vestigational } \\
\text { team }\end{array}$ & - \\
\hline Slovakia & yes & yes & yes & yes & - & yes & - \\
\hline Slovenia & \multicolumn{7}{|c|}{ no specific answer service by service } \\
\hline Spain & yes & yes & yes* $^{*}$ & - & 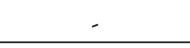 & yes & - \\
\hline Switzerland & \multicolumn{7}{|c|}{ no specific answer service by service } \\
\hline
\end{tabular}

\section{Discussion}

The most common answer from the countries "Other" to the first question could be interpreted as a kind of hesitance to give clear positive or negative answer. Some of the countries gave this answer because the patients may be treated at their home not by specialized companies, but only by their physicians and home care workers or nurses. This information correlates with some arguments to the responses of countries that gave a positive answer to this question.

Another listed reason for this answer "Other" was that the principal investigator must ensure the availability of appropriately instructed and trained staff in such case.

Some of the countries pointed out that it is allowed under restrictive conditions and in rare cases but cannot become a common practice. Other part of the countries clarified that their answer was not a clear "No, it isn' $t$ " but "Other" due to the lack of provisions to regulate the issue. Respectively, they gave answer "Other" because such opportunity was not explicitly forbidden by law.

Hence, in most countries it was not forbidden, and they indicated the opportunity of medical specialists to help patients at their home. The respondents reported such cases, but they pointed out that it was not considered a common practice in conducting clinical trials in their countries. Countries referred to applicable requirements: contract between the parties, delegated functions, proper notice in the Delegation $\log$, registration of the vendors etc. The responsibility and control of principal investigator according to the requirements of GCP should not be derogated.

Ireland referred to the national COVID-19 Guidance on the management of clinical trials during COVID-19. The Guidance states that "Where a subject is unable to attend the site, other measures, such as contact via phone or home nursing visit may be required to identify adverse events and ensure continuous medical care and oversight." ${ }^{\prime 2}$. 
Germany reported that in its territory there were a few specialized service companies that work with sponsors to integrate home visits into clinical trials.

Czech Republic gave a positive answer by referring to a national "Home Care" program. The "Home Care" program has been introduced during the COVID-19 pandemic whereby specialized service companies or medical care specialists may be included in the process of conducting clinical trials ${ }^{13}$. The Home Care provider cannot be engaged directly by the sponsor but a written contract between the provider of the healthcare facility (where the concerned trial site is located) and the Home Care provider must be signed. Such contract should specify responsibilities and competencies of the Home Care provider in the concerned clinical trial. The contract also contains a list of names of Home Care staff to be involved in the clinical trial. The listed staff should be included also in the investigator's Delegation Log at the trial site ${ }^{13}$. They believe that the "Home Care" program in clinical trials will be applicable in the country even after the end of the pandemic.

Regarding the relevant legislation, Austria pointed out as applicable Austrian Medicinal Product Act, as well as the Clinical Trial Regulation ${ }^{14}$. The responsibilities of physicians, nurses and home care workers in Austria were covered by the respective professional law. A similar answer was given by Slovakia and Latvia. Slovakia referred to the national Act No. 576/ 2004 Coll. on health care and healthcare-related services. Latvia indicated as applicable Cabinet Regulation No 555 regarding general medical care and services provided at patient's home. They however considered that this legislation falls within the national medical legislation only and not within the clinical trials legislation.

All the countries with answer "Other" to this optional question (following the first core question) referred to various applicable requirements and acts.

In Czech Republic, the patients must agree to the utilization of "Home Care" and "Home Care" may be included in the clinical trial if a number of conditions are met: the principal investigator must agree to it; trial subjects must not be exposed to a higher risk than that posed by the completion of the procedures at the trial site; the utilization of "Home Care" should be described in the protocol and the Informed Consent Form; an effective system of timely communication is needed; the procedures must be adequately documented and the relevant source documents must be stored; the responsibilities must be clear and noted in the Delegation Log, and Home Care must be covered by the insurance and formed in a written contract ${ }^{13}$.
Denmark referred to the ICH GCP, points 4.2.5 and 4.2.6 and Questions\&Answers Good Clinical Practice ${ }^{8,9}$. Currently Danish Medicines Agency's guidance on the implementation of decentralized elements in clinical trials with medicinal products is applicable ${ }^{15}$. The declared purpose of this guidance is to remain in force even after the end of COVID-19 pandemic. This guidance states that it is "divided into decentralized elements that can be included or excluded according to the study population and design" 15 .

In Estonia the requirements were regulated by Health Services Organization Act ${ }^{16}$. Nurses and health practitioners must be registered as healthcare providers and the company must have an appropriate activity license. The competent authority for the registration and authorization of activity license is the Republic of Estonia Health Board ${ }^{17}$.

Ireland responded that it applies European Medicines Agency's regulatory flexibilities and European Union and national guidance on the management of clinical trials during COVID-19 pandem$\mathrm{ic}^{10,12}$. A similar answer was given by Portugal, where European Union Guidance on the management of clinical trials during the COVID-19 pandemic and Guidance of the National Ethics Committee for Clinical Research are applicable.

Switzerland stated that the issue of clinical trials to be conducted off-site and at patient's home was not regulated. Basically, it was not forbidden. The principal investigator and sponsor work closely with the responsible ethics committee which reviews the suitability of the trial site. They pointed as applicable the Ordinance on Clinical Trials in Human Research of 20 September $2013^{18}$ (based on Human Research Act of 30 September $2011^{19}$ ), which regulates the requirements for conducting clinical trials and the authorization and notification procedures for clinical trials in Switzerland and ICH GCP ${ }^{8}$, in general and specifically - Joint Guidance of Swissmedic and Swissethics on the management of clinical trials with medicinal drug products in Switzerland dated 4.11.202020. The procedures described thereto were aligned to the requirements laid down in the European Union Guidance on the Management of Clinical Trials during the COVID-19 pandemic ${ }^{10}$.

The countries responded that all or some of the activities from $\mathrm{A}$ to $\mathrm{F}$ (Table 1) can be done as a home care at patient's home. They indicated their answer not in general as a rule, but based on the practice, after case-by-case assessment and depending on the trial's procedures and design ${ }^{21}$. The distribution of IMP to the patient's home was pointed by the respondents as applicable during the COVID-19 or at exceptional circumstances and restrictions. 
Regardless of the answers to the previous questions (Table 1), most of the countries responded negatively about the application of "site-less" model in clinical trials in their country.

The arguments of the countries which responded "Yes" corresponded with their experience from the practice basically. They stated that in principle their answer is "Yes" but shared that did not meet in the practice the clear example of the model (Denmark) or they associated this "site-less" model with the COVID-19 pandemic only (Slovenia and Hungary). When these countries were asked for additional information (optional question) on the relevant provisions and legislation, Denmark stated that their positive answer is based on the argument that this model is not specifically prohibited, whilst Slovenia and Hungary referred only to the European Union Guidance on the Management of Clinical Trials during the COVID-19 pandemic ${ }^{10}$. Some of the issues on the topic in Denmark are commented in a national document named "Extraordinary measures for clinical trials due to COVID-19"22.

Following the negative answer to the core question about the application of the "site-less" model, most of the countries identified as a limitation/prohibition the requirement clinical trials to be conducted at the trial sites at healthcare facilities only (Austria, Spain, Czech Republic, Germany, Finland, Portugal, and Romania). The other countries here stated that this case (site-less) was not regulated in the legislation or should be decided on a case-by-case basis under the relevant circumstances and that is why their answer was negative.

As an additional comment, Spain referred to a specific national instruction for conducting clinical trials in Spain ${ }^{23}$.

All the countries that responded to the question on the challenges in "site-less model" believed that various problems arise (grouped above into nine groups) and should be proper addressed and discussed.

Austria and Czech Republic did not give a clear answer "Yes" to the question if they consider that the combination of home and site visits is better than visits at site only, but they were more positive than negative in their answers. Portugal stated that it depends on the clinical trial disease, procedures, aims, phase, IMP, patients and did not give specific positive or negative answer. Hence, these three countries could be count as a part of the group with positive opinion on the question. It can be concluded that all the countries that responded to this question considered that the combination of in-clinic and home visits can be better than only visits at sites. Basically, this could be explained by their experience and knowledge of the pandemic or other cases from their practice.

\section{The limitations of the study}

The survey was conducted in the period December 2020 - February 2021 by email communication with employees of the National Competent Authority on medicines of 16 European countries. Because of the nature of the survey, it obtained non-official opinions; the study did not analyse the official position of the national competent authorities. Future studies based on a formal approach can establish official relevant guidelines and legislation.

\section{Conclusions}

Based on this research, the implementation of the decentralized elements in the clinical trials in Europe is often based on a case-by-case evaluation only. The European countries believe that the hybrid model of the clinical trials can be better than the traditional model, with visits only at clinical sites. Notwithstanding the application of various national requirements and acts, they are either fragmentary, or not specifically applicable for such cases. In Bulgaria, there are also no specific rules and legislation for regulation of the listed issues and the topic in general.

Nowadays, the decentralized elements in clinical trials are associated mostly with exceptional circumstances because of the COVID-19 pandemic. The challenges raised by the COVID-19 pandemic had a profound impact on the management of clinical trials and the lessons one can learn from them are numerous. Further discussion and appropriate regulation on decentralized clinical trials will lead to consistent and significant benefits for the patients in the future.

\section{Author Contributions:}

Conceptualization, V.G., A.S. and D.S.; methodology, V.G. and D.S.; software, V.G; validation, D.S.; formal analysis, V.G., A.S. and D.S.; investigation, V.G.; resources, V.G; data curation, D.S.; writing-original draft preparation, V.G.; writing-review and editing, A.S and D.S.; visualization, V.G; supervision, D.S.; project administration, V.G. All the authors have read and agreed with the final version of the article.

\section{Compliance with Ethics Requirements:}

"The authors declare no conflict of interest regarding this article"

"The authors declare that all the procedures and experiments of this study respect the ethical standards in the 
Helsinki Declaration of 1975, as revised in 2008(5), as well as the national law"

"No funding for this study"

\section{Acknowledgements:}

None

\section{References}

1. World Health Organization, Home Care across Europe. Current structure and future challenges (2012). Available at https://www.euro.who.int/__data/assets/pdf_ file/0008/181799/e96757.pdf (accessed September 12, 2021).

2. Van Norman GA, Decentralized clinical trials. The future of medical product development? JACC Basic to Translational Science. 2021;6(4):384-387.

3. European Medicines Agency. Reflection paper on expectations for electronic source data and data transcribed to electronic data collection tools in clinical trials. Available at https://www.ema.europa.eu/en/documents/regulatory-procedural-guideline/reflection-paper-expectations-electronic-source-data-data-transcribed-electronic-data-collection_en.pdf (accessed September 12, 2021).

4. European Commission, Question and Answers on the interplay between the Clinical Trials Regulation and the General Data Protection Regulation. Available at QA data protection and clincial trials_for consulation final (europa. eu) (accessed September 12, 2021).

5. Walz M, How Real World Data, Decentralized Trials, and Diversity Will Put the Patient First, Available at https:// www.pharmoutsourcing.com/Specialty/Clinical_Trials/ Featured-Articles/576442-How-Real-World-Data-Decentralized-Trials-and-Diversity-Will-Put-the-Patient-First/? cf_chl_jschl_tk__=pmd_MdTwlelanuynRFk3UC32BB3zCcJNFDo3pnUUrSs2snc-1629749120-0-gqNtZGzNAqWjenBszQi9 (accessed September 12, 2021).

6. Sommer C, Zuccolin D, Arnera V, et al. Building clinical trials around patients: evaluation and comparison of decentralized and conventional site models in patients with low back pain. Contemp Clin Trials Commun. 2018;11:120-126.

7. Tan AC, Ashley DM, Khasraw M. Adapting to a pandemic-conducting oncology trials during the SARS-CoV-2 pandemic. Clin Cancer Res. 2020; 26(13): 3100-3103.

8. ICH Good Clinical Practice E6 (R2), https://www.ema. europa.eu/en/ich-e6-r2-good-clinical-practice\#current-version--revision-2-section (accessed September 12, 2021).

9. Q\&A Good Clinical Practice, Q10, Q11. Available at https://www.ema.europa.eu/en/human-regulatory/research-development/compliance/good-clinical-practice/ qa-good-clinical-practice-gcp (accessed September 12, 2021).

10. Guidance on the management of clinical trials during the COVID-19 (coronavirus) Pandemic, version 4. Available at https://ec.europa.eu/health/sites/default/files/files/ eudralex/vol-10/guidanceclinicaltrials_covid19_en.pdf (accessed September 12, 2021).

11. Points to consider on implications of coronavirus disease (COVID-19) on methodological aspects of ongoing clinical trials. Available at https://www.ema.europa.eu/en/ implications-coronavirus-disease-covid-19-methodologi- cal-aspects-ongoing-clinical-trials\#current-version-section (accessed September 12, 2021).

12. Guidance on the management of clinical trials during COVID-19, Ireland. Available at http://www.hpra.ie/homepage/medicines/regulatory-information/clinical-trials/ covid-19-(coronavirus)-and-cts/guidance-on-the-management-of-clinical-trials-during-covid-19/ (accessed September 12, 2021).

13. Opinion of SÚKL's Department of Clinical Trials on Medicinal Products on Ongoing Clinical Trials and To-Be-Commenced Clinical Trials in Light of the COVID-19 Epidemiological Situation of 22 December 2020, Czech Republic. Available at https://www.sukl.eu/ medicines/opinion-of-sukl-s-department-of-clinical-trials-on-medicinal-1 (accessed September 12, 2021).

14. Regulation (EU) No 536/2014 of the European Parliament and of the Council of 16 April 2014 on clinical trials on medicinal products for human use and repealing Directive 2001/20/EC (OJ L 158, 27.5.2014). Available at https:// eur-lex.europa.eu/legal-content/EN/TXT/?uri=CELEX\% 3A02014R0536-20140527 (accessed September 12, 2021)

15. Danish Medicines Agency's guidance on the implementation of decentralized elements in clinical trials with medicinal products, 04 May 2021, Version 1.0, Danish Medicines Agency, Denmark. Available at 5A96356760ED408CBFA9F85784543B53.ashx (laegemiddelstyrelsen.dk) (accessed September 12, 2021).

16. Health Services Organization Act, Estonia, RT I 2001, 50, 284. Available at https://www.riigiteataja.ee/en/ eli/518052020003/consolide (accessed September 12, 2021).

17. Republic of Estonia Health Board, Registration of health care professionals. Available at https://www.terviseamet. ee/en/healthcare/registration-of-health-care-professionals (accessed September 12, 2021).

18. Ordinance on Clinical Trials in Human Research of 20 September 2013, Switzerland. Available at CC 810.305 (admin.ch) (accessed September 12, 2021).

19. Federal Act on Research involving Human Beings (Human Research Act, HRA) of 30 September 2011, SR 810.30, Switzerland. Available at https://www.fedlex.admin.ch/ eli/cc/2013/617/en (accessed September 12, 2021).

20. Joint Guidance of Swissmedic and swissethics on the management of clinical trials with medicinal drug products in Switzerland, version 2.4, Switzerland. Available at https://www.swissmedic.ch/swissmedic/en/home/news/ coronavirus-covid-19/klv-cov-2-pandemie-2.html (accessed September 12, 2021).

21. ICH General Considerations for clinical trials E8. Available at https://database.ich.org/sites/default/files/ E8_Guideline.pdf (accessed September 12, 2021).

22. Extraordinary measures for clinical trials due to COVID-19. Denmark. Available at https://laegemiddelstyrelsen.dk/ en/news/2020/extraordinary-measures-for-clinical-trials-due-to-covid-19/ \%media/259AC11DD4CB438F9966E 0C06396E47A.ashx (accessed September 12, 2021).

23. Instruction document of the Spanish Agency of Medicines and Medical Devices for conducting clinical trials in Spain, Version 12. Spain. Available at https://www.aemps.gob.es/ medicamentos-de-uso-humano/investigacionclinica_medicamentos/ensayosclinicos/\#n-espanola (accessed September 12, 2021). 


\section{ANNEX 1. QUESTIONNAIRE}

This survey is a scientific informal study that aims to evaluate your opinion and experience regarding decentralized clinical trials or decentralized elements in clinical trials. We will highly appreciate if you respond to the questions below. Please answer all the core questions and give additional information to the next question according to your answer (if applicable).

Thank you!

\section{Questions:}

1. Is it possible in your country that specialized service companies or medical care specialists work with sponsors and investigators to help patients (at their home) in the process of conducting clinical trials?

A. Yes, it is possible (please explain)

B. No, it isn't (please explain)

C. Other (please explain)

2. If the answer of Question 1 is positive, what is the regulation of this kind of service/companies?

A. The regulation is a part of the national Medicines Act/clinical trials legislation

B. The regulation is a part of the national trade/commercial law

C. The regulation is a part of the national medical legislation

D. Other (please explain, for example rules/law for the duration of the COVID-19 Pandemic only)

Please put the provisions in English or if there is no English version - in the national language.

3. What services are allowed to be provide as a home care/in the patient home. Please underline the applicable:
A. Treatments' administration
B. Monitoring outcomes in the patient home
C. Distribution of Investigational medicinal product (IMP)
D. Laboratory specimen collection and processing
E. Preparation of IMP
F. Assessment of adverse events and reporting
G. Other (please explain)

4. Is the Siteless model of clinical trials applicable in your country?

A. Yes, it is (please explain)

B. No, it isn't (please explain)

5. If the answer of Question 4 is "Yes", what is the regulation, relevant provisions or/and guidelines? Please explain/put the rules in English or if there is no English version - in the national language:

6. If the answer of Question 4 is "No", what are the limitations/prohibition? Please explain/put the text in English or if there is no English version - in the national language:

7. What are the main challenges in Siteless Clinical Trials model and Study Home Nursing in the light of your country specifics and/or national legislation? Please explain (for example with reference to personal data security, missing proper training for patients/specialists, conflict with provisions, rejection and patient resistance, etc.)

8. Do you consider that the combination of on-site and home visits is better than visits at site only?
A. Yes, it is (please, explain why)
B. No, it isn't (please, explain why)

*If you have additional comments on the topic, they are welcome and you can make them here 